\title{
Correction to: A controllable deflection routing and wavelength assignment algorithm in OBS networks
}

\author{
Philani Khumalo $^{1} \cdot$ Bakhe Nleya $^{1}$ (D) Andrew Mutsvangwa ${ }^{1}$
}

Published online: 24 December 2019

(C) The Optical Society of India 2019

\section{Correction to: J Opt (December 2019) 48(4):539-548 https://doi.org/10.1007/s12596-019-00578-2}

The article, A controllable deflection routing and wavelength assignment algorithm in OBS networks, written by Philani Khumalo, Bakhe Nleya, Andrew Mutsvangwa, was originally published electronically on the publisher's Internet portal (currently SpringerLink) on 23 November
2019 with open access. With the author(s)' decision to step back from Open Choice, the copyright of the article changed on 19 December 2019 to ( ) The Optical Society of India 2019 and the article is forthwith distributed under the terms of copyright.

Publisher's Note Springer Nature remains neutral with regard to jurisdictional claims in published maps and institutional affiliations.

The original article can be found online at https:// doi.org/10.1007/s12596-019-00578-2.

Bakhe Nleya

bmnleya@gmail.com

Philani Khumalo

philanipk@gmail.com

Andrew Mutsvangwa

amutsvangwa@gmail.com

1 Faculty of Engineering, Durban University of Technology, Durban, South Africa 